\title{
THE IMPACT OF TECHNICAL ANALYSIS OF MEDICAL PRESCRIPTIONS ON AN ASSISTED THERAPY SERVICE IN BRAZIL
}

Luiz Claudio Ramos de Albuquerque ${ }^{1, \star}$, Reno Martins Coelho², Bárbara Rodrigues Campagnuci Rebouças², Camila da Silva Batista ${ }^{2}$, Luciano Allan Agra dos Santos ${ }^{1}$, Vanessa Karine Bispo Macedo ${ }^{1}$, Samille Maria Bandeira Freitas Pacheco ${ }^{1}$

1.Acredite - Gestão, Estratégia e Qualidade, Maceió (AL), Brazil; 2.CID - Grupo, Rio de Janeiro (RJ), Brazil.

*Corresponding author: claudio@acreditequalidade.com

\section{BACKGROUND}

According to ANVISA (2004), assistance pharmaceuticals is a set of actions directed to the promotion, protection and recovery of health, both individual and collective, taking the medicine as input essential and aimed at the access and to their use rational. Shares of assistance pharmaceuticals involve the attention pharmaceuticals which is the interaction direct the pharmacist to the patient aiming one pharmacotherapy rational and achievement of results defined and measurable, geared to improving the quality of life of the patient. Among the actions is the analysis technique of prescriptions medical in which the pharmacist evaluates the prescription as a safe drug, pharmacotherapy, indication, interactions drug, possible reactions adverse, etc.

\section{METHODS}

Descriptive, exploratory study with survey data by means of the report of monitoring of indicators of pharmacy practice with the compilation of analysis techniques of provisions made at CID Group (Rio de Janeiro) and the monitoring of the impact of this action on the needs of intervention pharmaceuticals in the course of the months of January to May of the year 2021.

\section{RESULTS}

In January, it was possible to perform a preliminary analysis of prescriptions in $91 \%$ of patients, which represents a value very close to the target of $90 \%$. With this data monitored, it was possible to gradually raise this result to $96 \%$ by the month of May. Of these, the following items were evaluated: dose prescribed in mass (mcg; mg; g); dilution; route of administration; infusion time; dosage. Of the prescriptions evaluated in January, $41 \%$ were fully conformity while in May they rose to $48 \%$. It is noteworthy that only $2 \%$ of these noncompliances were limiting for the follow-up of infusion therapy, unlike the scenario in January, which was $4 \%$. Of the interventions performed, $40 \%$ across adjustments to the infusion time; dilution adjustment $20 \%$; product $20 \%$ and nonstandard inclusion of pre-medication $20 \%$.

\section{CONCLUSION}

Through the realization of the analysis technique of prescriptions prior to infusion noted is the evolution of the conformity of these, she is known to increase the safety of the patient, the efficiency operating in the flow of the same by avoiding rescheduling, delays the infusion, etc., resulting in raising the degree of reliability of the institution.

\section{KEYWORDS}

Pharmaceutical care, Technical analysis, Medical prescriptions, Assisted therapy service, Infusion center. 